\title{
Synthesis and characterization of mesoporous crystalline copper metal-organic frameworks for electrochemical energy storage application
}

\author{
B. M. Omkaramurthy ${ }^{1} \cdot$ G. Krishnamurthy ${ }^{1} \cdot$ Sabine Foro $^{2}$
}

Received: 11 October 2019 / Accepted: 15 January 2020 / Published online: 5 February 2020

(c) Springer Nature Switzerland AG 2020

\begin{abstract}
The mesoporous nanostructure Cu-metal organic frameworks (Cu-MOF-1 and Cu-MOF-2) have been synthesized by a high temperature solvothermal route. The products were characterized by X-ray diffraction, Brunauer-Emmett-Teller surface measurement, Thermo gravimetric analysis, scanning electron microscope and Single crystal XRD. The electrochemical properties of these MOF electrodes were examined by using of cyclic voltammetry (CV), galvanostatic charge-discharge (GCD) and electrochemical impedance spectroscopic techniques. Comparing the results of CV and GCD studies, both those MOFs have shown significant charge storage capacity, while Cu-MOF-2 has showed a specific capacitance greater than Cu-MOF-1. The Cu-MOF-1 and Cu-MOF-2 electrodes showed a maximum specified capacity of 181 and $248 \mathrm{~F} \mathrm{~g}^{-1}$ respectively at a current density of $1 \mathrm{~A} \mathrm{~g} \mathrm{~g}^{-1}$ and an extensive cyclic stability of up to 2000 cycles with capacity retention of $\sim 90.1 \%$. The electrochemical studies with Cu-MOF electrodes were conducted in $6 \mathrm{M} \mathrm{KOH}$ electrolytes. The excellent electrochemical properties of Cu-MOFs can be credited to the large surface area with a high microporous volume of structurally implanted electro-active metallic centres and the rapid transport of ions into electrolytes/electrodes. The results imply that the Cu-MOFs electrode could be the potentially high- performance electrode materials for super capacitor applications.
\end{abstract}

Keywords Mesoporous Cu-MOFs · Crystal structure · Cyclic voltammetry · Super capacitor · Specific capacitance

\section{Introduction}

Metal organic frame works (MOFs) are a recent type of crystalline porous materials that can be formed by the cluster of organic ligands and metallic ions from simple room temperature stirring to high temperature solvother$\mathrm{mal} /$ hydrothermal heating methods [1-6]. Accordingly by careful selection of metal ions and organic ligands with distinct coordination geometries can play major role in design to synthesize the MOFs. In the earlier few years, polycarboxylate organic ligands can function as exceptional organic building blocks, pertaining to their strong coordination abilities and variable coordination modes.
On the other hand, the MOFs have received considerable attention in recent years due to their highly porous and three-dimensional hybrid structure possessing interesting electronic properties $[7,8]$. The redox behaviour of metal cation in MOFs makes electrode materials promising in energy storage devices such as lithium ion batteries and supercapacitors, especially pseudo capacitors $[9,10]$. Supercapacitors are one of the promising energy storage devices with high power density, long service life and low cost correlated to conventional batteries and long cycle life. One specific type of supercapacitor is called doublelayer electrical supercapacitors (EDLCs), which usually use carbon electrode materials with increased surface

G. Krishnamurthy, drgkmurthy.bub@gmail.com | 'Department of Studies in Chemistry, Bangalore University, Bangalore 560 056, India. ${ }^{2}$ Institute of Materials Science, Darmstadt University of Technology, Alarich-Weiss-Str. 2, 64287 Darmstadt, Germany. 
Scheme 1 Scheme for the formation of Cu-MOF-1 and Cu-MOF-2

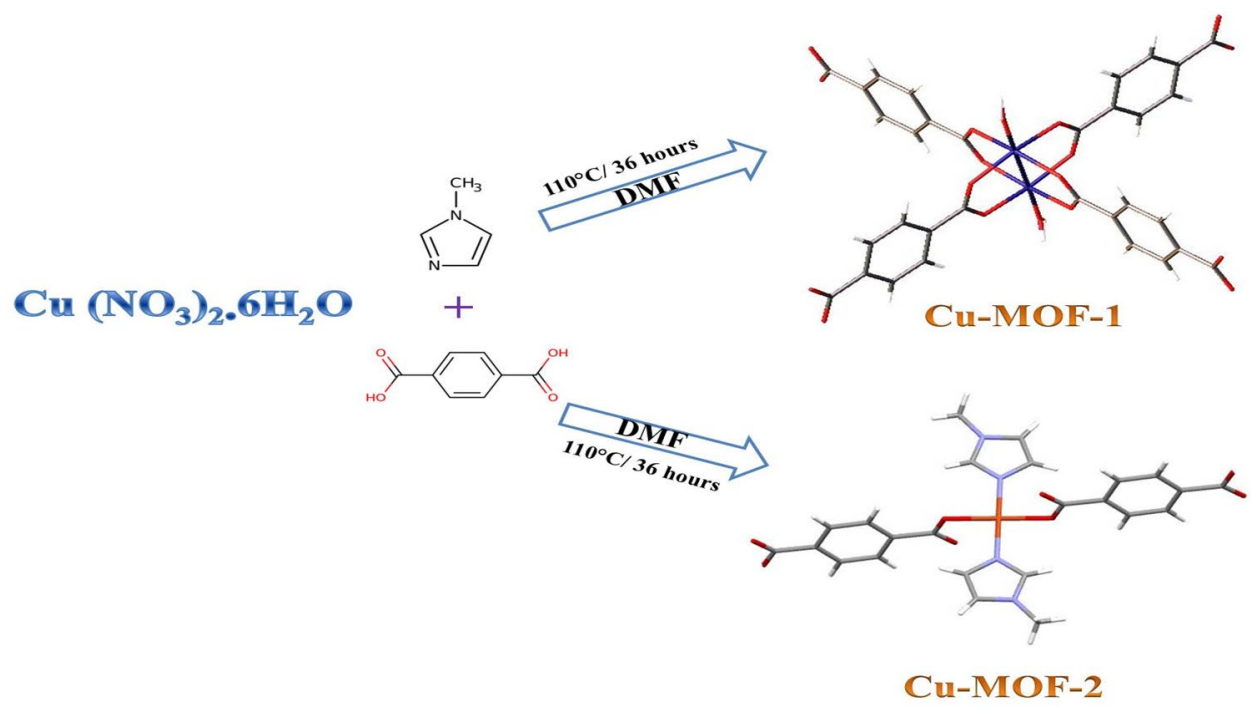

area and porosity. However, both the physically stored charges and the energy density of EDLCs are very low. In addition, pseudo capacitors with electrochemically active materials, including metal oxides/sulphides with increased energy density, have received greater attention in recent years $[11,12]$. Unfortunately, due to their poor conductivity $[13,14]$, the electrochemical application of MOFs is still less. Copper-1,3,5-benzenetricarboxylate $\left(\mathrm{Cu}_{3}(\mathrm{BTC})_{2}\right.$, also called MOF-19 or HKUST-19), showed an exciting behaviour in electrochemically centred supercapacitors because of its high surface area and huge pore volume [15-18]. So far, only some reports for supercapacitors exist based on Cu-MOF, Srimuk et al. [19]. Electrochemical behaviour published for supercapacitors of HKUST-1 with a specific capacity of less than $50 \mathrm{~F} \mathrm{~g}^{-1}$. Saraf et al. [20]. Later on the $\mathrm{Cu}-\mathrm{MOF}$ was used as a supercapacitor electrode material and attained a specific maximum capacity of $85 \mathrm{~F} \mathrm{~g}^{-1}$ at current densities of $1.6 \mathrm{~A} \mathrm{~g}^{-1}$. Both have been based on $\mathrm{Cu}_{3}$ (BTC) ${ }_{2} 3 \mathrm{H}_{2} \mathrm{O}$. Cu-MOF is used as water/ethanol solvent and water/DMF solvents [21,22]. This paper represents for the synthesis of new $\mathrm{Cu}$ - MOFs with DMF mixed ligands as a single solvent $[\mathrm{Cu}(\mathrm{BDC})(\mathrm{MI})(\mathrm{DMF})](\mathrm{BDC}=$ benzene-1,4-dicarboxylic acid, $\mathrm{MI}=1$-methyl imidazole and $\mathrm{DMF}=N, \mathrm{~N}$ dimethylformamide). Benzene-1,4-dicarboxylic acid (BDC) are considered to be hard ligands, so form strong bonds with hard metal centres. The main choices of metals used to bind to carboxylate are transition metals, which can form a wide variety of coordination geometries affording many different network architectures. Carboxylic acids are also attractive as framework-forming reagents because their high acidity ( $\mathrm{pKa} \sim 4$ ) allows facile in situ deprotonation. The solvent DMF used in the assembly process may participate in coordination with metal ions or can also act as a guest molecule in the final lattice structure. Although most often the solvents may not be incorporated in the as-synthesized MOF, they act as a structure directing agent or a medium for the crystal growth process, i.e., the extent of deprotonation of organic carboxylate ligands can be controlled by selecting suitable solvents such as DMF, DEF and DMA or by adjusting the basicity of solvent medium. These solvents can be converted to its corresponding amines at higher temperatures and thus lead to deprotonation of carboxylate.

The electrochemical and electro catalytic properties of these $\mathrm{Cu}$ - MOF are investigated in $6 \mathrm{M} \mathrm{KOH}$ (alkaline media) solutions. Because of the improved electrochemical behaviour of copper, benzene-1,4-dicarboxylic acid and imidazole, the synthesis of Cu-MOF-1 and Cu-MOF-2 using solvent DMF is reported using a solvothermal method. To the best of our knowledge, the synthesized Cu-MOF-1 and Cu-MOF-2 have been analyzed as highperformance electrode materials. These results show that as - synthesized Cu-MOF-1 and Cu-MOF-2 can be used as a new material for the storage of energy (Scheme 1).

\section{Experimental}

\subsection{Materials}

All chemicals used in this research work, such as copper nitrate hexahydrate $\left(\mathrm{Cu}\left(\mathrm{NO}_{3}\right)_{2} \cdot 6 \mathrm{H}_{2} \mathrm{O}\right)$, benzene1,4-dicarboxylic acid $\left(\mathrm{H}_{2} \mathrm{BDC}\right)$, methyl imidazole (MI) and $\mathrm{N}, \mathrm{N}$-dimethylformamide (DMF), were analytical grade and obtained from SDFCL (SD fine chemistry limited). Methylimidazole and chloroform were reagent grade chemicals obtained from Spectrochem Private limited. All these chemicals were used without further purification as received. 


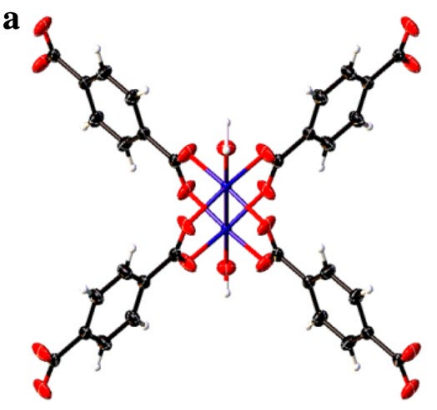

b

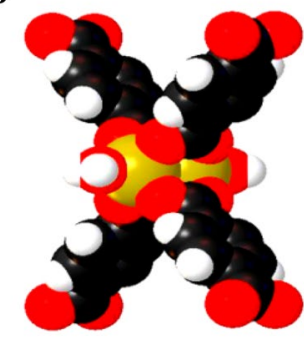

Fig. 1 a Crystal structure and b space filled diagram of Cu-MOF-1

\subsection{Synthesis procedure}

\subsubsection{Cu-MOF-1}

The solutions of $\mathrm{Cu}\left(\mathrm{NO}_{3}\right)_{2} \cdot 6 \mathrm{H}_{2} \mathrm{O}$ (1.0 gm), Benzene-1,4-dicarboxylic acid $(0.70 \mathrm{gm})$ were prepared separately by dissolving in $15 \mathrm{ml}$ DMF each under mild stirring until the formation of a clear solution. The mixture of the above solutions was then transferred to a steel autoclave fitted with Teflon (capacity $60 \mathrm{ml}$ ) inner vessel. The tight sealed autoclave was heated to $110^{\circ} \mathrm{C}$ and maintained for $36 \mathrm{~h}$ and later it was left to cool naturally to room temperature. The product formed was washed sequentially with DMF, ethanol and chloroform and dried in a vacuum oven $70^{\circ} \mathrm{C}$ for $12 \mathrm{~h}$.

\subsubsection{Cu-MOF-2}

The precursors such as $\mathrm{Cu}\left(\mathrm{NO}_{3}\right)_{2} \cdot 6 \mathrm{H}_{2} \mathrm{O}(1.0 \mathrm{gm})$, Benzene1,4-dicarboxylic acid $(0.70 \mathrm{gm})$ were dissolved in $15 \mathrm{ml}$ of DMF separately under mild stirring. To the above mixture added about $0.5 \mathrm{ml}$ of 1-methylimidazole to obtain a clear solution. The mixture was subsequently transferred to a $60 \mathrm{ml}$ Teflon lined steel autoclave. The sealed autoclave was heated at $110^{\circ} \mathrm{C}$ for about $36 \mathrm{~h}$ and cooled naturally to room temperature.

\subsection{Characterization techniques}

The above products were characterized by vibrational properties of the functional groups were studied by the
Table 1 Crystal data and structure refinement for Cu-MOF-1 and Cu-MOF-2

\begin{tabular}{|c|c|c|}
\hline Empirical formula & $\mathrm{C}_{12} \mathrm{H}_{6} \mathrm{CuO}_{5}$ & $\mathrm{C}_{16} \mathrm{H}_{16} \mathrm{CuN}_{4} \mathrm{O}_{4}$ \\
\hline Formula weight & 293.71 & 391.87 \\
\hline Temperature/K & 293(2) & 293(2) \\
\hline Crystal system & Monoclinic & Monoclinic \\
\hline Space group & $\mathrm{C} 2 / \mathrm{m}$ & $P 2_{1} / c$ \\
\hline $\mathrm{a} / \AA$ & $12.820(1)$ & $5.3043(7)$ \\
\hline $\mathrm{b} / \AA ̊ \AA$ & $15.649(1)$ & $14.720(2)$ \\
\hline$c / \AA ̊$ & $6.8289(5)$ & $11.0659(9)$ \\
\hline$a /^{\circ}$ & 90 & 90 \\
\hline$\beta /^{\circ}$ & $111.366(9)$ & $104.90(1)$ \\
\hline$\gamma /{ }^{\circ}$ & 90 & 90 \\
\hline Volume $/ \AA^{3}$ & $1275.86(17)$ & $834.97(18)$ \\
\hline Z & 4 & 2 \\
\hline$\rho_{\text {calc }} \mathrm{g} / \mathrm{cm}^{3}$ & 1.529 & 1.559 \\
\hline$\mu / \mathrm{mm}^{-1}$ & 1.719 & 1.337 \\
\hline$F(000)$ & 588.0 & 402.0 \\
\hline Crystal size $/ \mathrm{mm}^{3}$ & $0.160 \times 0.160 \times 0.080$ & $0.440 \times 0.080 \times 0.060$ \\
\hline Radiation & $\operatorname{MoKa}(\lambda=0.71073)$ & $\operatorname{MoKa}(\lambda=0.71073)$ \\
\hline $2 \theta$ range for data collection $/^{\circ}$ & 5.206 to 52.732 & 6.72 to 52.742 \\
\hline Index ranges & $-15 \leq h \leq 16,-13 \leq k \leq 19,-8 \leq \mathrm{I} \leq 7$ & $-6 \leq h \leq 6,-16 \leq k \leq 18,-13 \leq \mathrm{l} \leq 13$ \\
\hline Reflections collected & 2437 & 3091 \\
\hline Independent reflections & $1356\left[R_{\text {int }}=0.0188, R_{\text {sigma }}=0.0333\right]$ & $1711\left[R_{\text {int }}=0.0207, R_{\text {sigma }}=0.0348\right]$ \\
\hline Data/restraints/parameters & $1356 / 9 / 89$ & $1711 / 0 / 116$ \\
\hline Goodness-of-fit on $\mathrm{F}^{2}$ & 1.099 & 1.044 \\
\hline Final $R$ indexes $[I>=2 \sigma(I)]$ & $R_{1}=0.0559, w R_{2}=0.1691$ & $\mathrm{R}_{1}=0.0381, \mathrm{wR}_{2}=0.0820$ \\
\hline Final $R$ indexes [all data] & $\mathrm{R}_{1}=0.0675, \mathrm{wR}_{2}=0.1776$ & $\mathrm{R}_{1}=0.0608, \mathrm{wR}_{2}=0.0896$ \\
\hline Largest diff. peak/hole/e $\AA^{-3}$ & $1.16 /-0.66$ & $0.30 /-0.41$ \\
\hline
\end{tabular}




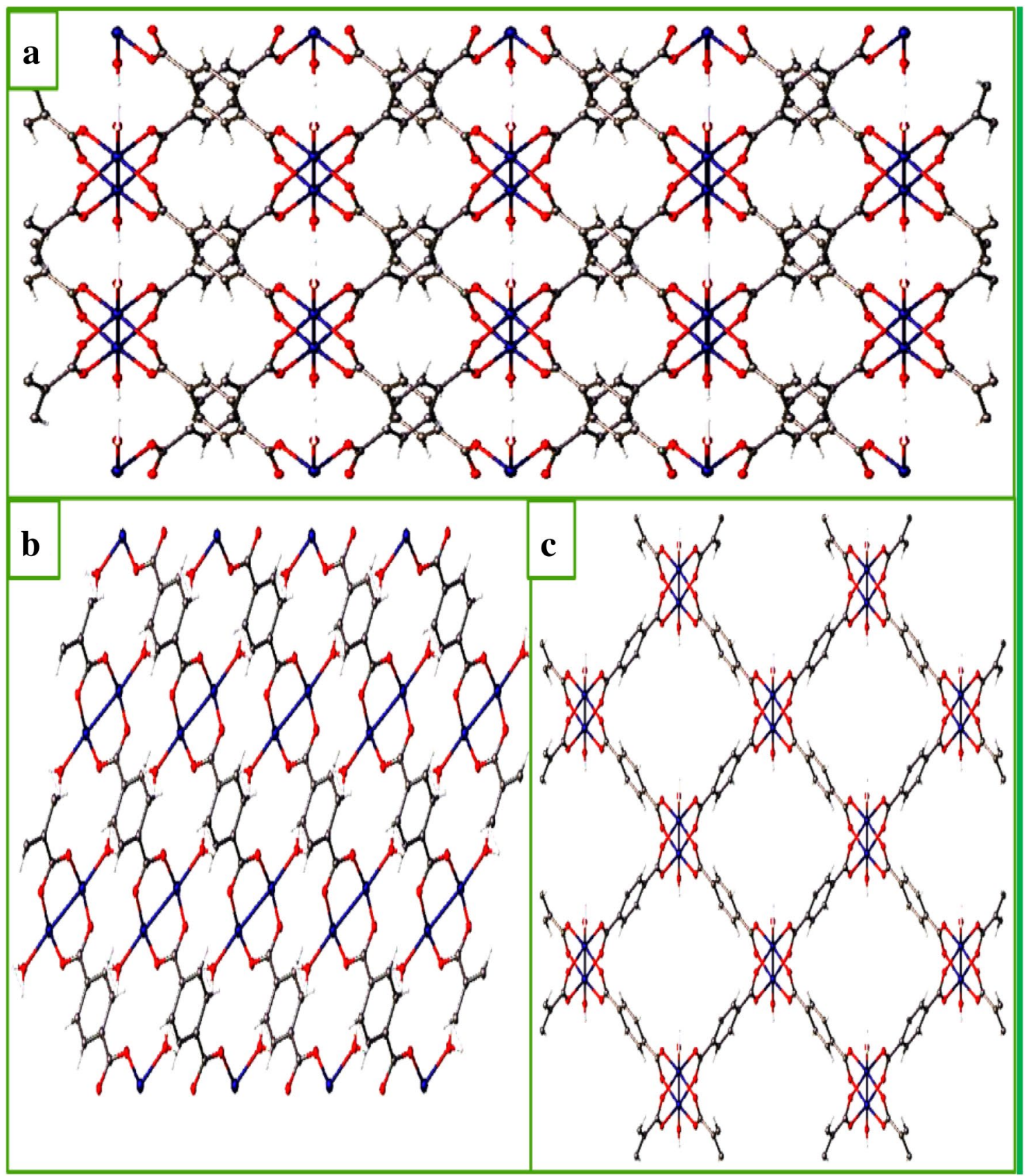

Fig. $2 \mathbf{a}, \mathbf{b}$ and $\mathbf{c}$ are the views of the coordination environment of Cu-MOF-1 with different axis $X, Y, Z$ (symmetry transformations used to generate equivalent atoms: $\# 1-x+1, y,-z+1 \# 2-x+1,-y,-z+1 \# 3 x,-y, z \# 4-x+1 / 2,-y+1 / 2,-z)$

Shimadzu 8400S FTIR spectrophotometer with IR grade $\mathrm{KBr}$ pellets in the range of $400-4000 \mathrm{~cm}^{-1}$. Powder $X-$ ray diffraction (PXRD) to obtain information on phase structure, purity, nature (crystalline or amorphous), etc. A Bruker D8 Advance X-CuKa radiation diffractometer was used and the $\mu=0.1541874 \mathrm{~nm}$. The FE-SEM images were taken on the Zeiss FESEM instrument. The pore size, the pore volume and the specific material surface area were calculated using the data obtained by Nova1000 BET instrument. Thermo gravimetric analysis (TGA) on a Perkin-Elmer thermal analyzer was carried out in the $\mathrm{N}_{2}$ atmosphere at a heating rate of $20^{\circ} \mathrm{C} \mathrm{min}^{-1}$. The crystal data was collected at the Xcalibur, Eos and Nova diffractometer. During data collection, the crystal was maintained at 293(2) K. The structure was solved using Intrinsic Phasing with the ShelXT structure solution program using 


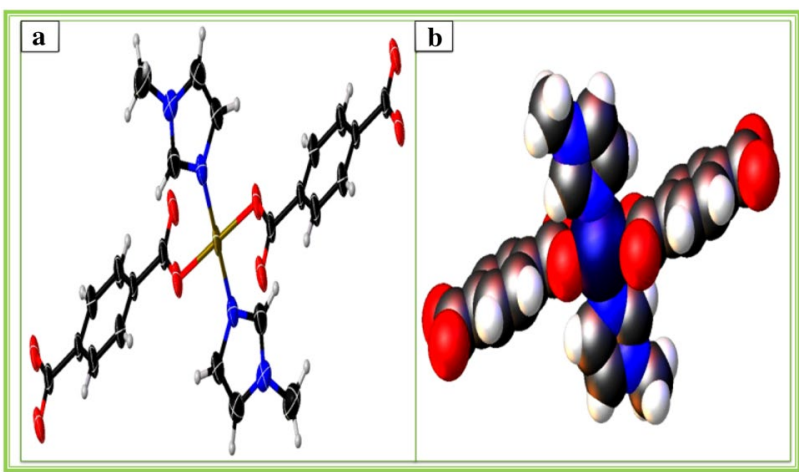

Fig. 3 a Crystal structure and b Space filled diagram of Cu-MOF-2

Olex2 and refined using the ShelXL refining package to CGLS minimization.

\subsection{Electrochemical measurements}

All electrochemical tests have been performed at the $\mathrm{CHI}$ $660 \mathrm{E}$ electrochemical workstation. The working electrode was prepared with a known quantity of active material (80 wt $\%$ or $\sim 2 \mathrm{mg}$ ) was prepared with graphite powder (15 wt\%) and polytetrafluoroethylene (PTFE) binder (5 wt\%) along with an ethanol. This mixture was consequently hand pressed on nickel mesh from all sides. Copper wire was used as the current collector. This electrode was left for drying at room temperature for about $24 \mathrm{~h}$. The cyclic voltammetry, galvanostatic charge-discharge, and electrochemical impedance spectroscopy were conducted under atmospheric conditions in $6 \mathrm{M} \mathrm{KOH}$ electrolyte solution. The saturated calomel electrode (SCE), platinum electrode and prepared Cu-MOF-1 and Cu-MOF-2 electrodes were used as the reference, counter and working electrodes respectively.

\section{Results and discussion}

\subsection{Crystal structure of Cu-MOF-1 and Cu-MOF-2}

\subsubsection{Single crystal X-ray diffraction (SXRD) studies of [Cu-MOF-1]}

The SXRD study of CU-MOF-1 has revealed that Cu (II) ion forms paddle- wheel units in which the four carboxylate groups are equatorial and two water molecules are axial. Therefore, each unit exists of two $\mathrm{Cu}$ (II) six-coordinated units with distorted octahedral geometries. Each $\mathrm{Cu}$ (II) dimeric unit co-ordinates with eight oxygen's from four carboxylate groups of four bdc ligands that can be unraveled as a 4-connected dimeric copper unit (Fig. 1a) and space filled diagram of Cu-MOF-1(Fig. 1b).

Crystal data for Cu-MOF-1: The Molecular formula is $\mathrm{C}_{12} \mathrm{H}_{6} \mathrm{CuO}_{5}$; Analysis made at $293.71 \mathrm{~K}$ : monoclinic, space group $C 2 / m$ with $a=12.820(1) \AA, b=15.649(1) \AA$, $c=6.8289(5) \AA, \beta=111.366(9)^{\circ}, V=1275.86(17) \AA^{3}, Z=4$, $T=293(2) \mathrm{K}, \mu(\mathrm{MoKa})=1.719 \mathrm{~mm}^{-1}$ and Dcalc $=1.529 \mathrm{~g} /$ $\mathrm{cm}^{-3}$. The structure was solved by direct methods and refined to a standard discrepancy index of $R=0.0188$ and $\mathrm{RW}=0.0333$ for 2437 reflections with $\mathrm{F} 2 \sigma(\mathrm{F})$ and a goodness of fit on $\mathrm{F}^{2}=1.093$ (Table 1).

In the structure, the $\mathrm{Cu}(\mathrm{II})$ ion is connected by two BDC groups and each group connects two dimmers to form a 1D frame works (Fig. 2a), which were specified together with $x, y$ and $z$ axis to form 1D, 2D and 3D channels with a diameter of $12 \AA$ (Fig. 2b, c).

\subsubsection{Crystal structure of [Cu-MOF-2]}

From the studies, it is found that the structure has $\mathrm{Cu}$ (II) ion forming pyramidal units, in which the two carboxylate groups are located in equatorial positions and two imidazole moieties occupy equatorial positions. Each $\mathrm{Cu}$ (II) monomer unit co-ordinates with two carboxylate and two imidazole groups with four oxygen atoms in Cu-MOF-2 (Fig. 3a) and the Cu-MOF-2 space filled diagram (Fig. 3b).

Crystal data for Cu-MOF-2: the molecular formula is $\mathrm{C}_{16} \mathrm{H}_{16} \mathrm{CuN}_{4} \mathrm{O}_{4}$; analysis temperature-293.71 K: monoclinic, space group $-P 2_{1} / c$ with lattice parameters: $a=5.3043(7) \AA, b=14.720(2) \AA, c=11.0659(9) \AA$, $\beta=104.90(1)^{\circ}, V=834.97(18) \AA^{3}, Z=2, T=293(2) \mathrm{K}, \mu$ $($ MoKa $)=1.337 \mathrm{~mm}^{-1}$ and Dcalc $=1.559 \mathrm{~g} / \mathrm{cm}^{3}$. The structure was solved by direct methods and refined to a standard discrepancy index of $R=0.0207$ and $R w=0.0348$ for 3091 reflections with $F 2 \sigma(F)$ and a goodness of fit on $F^{2}=1.093$ (Table 1).

The anisotropic thermal parameters of $\mathrm{Cu}-\mathrm{MOF}-1$ and Cu-MOF-2 have been refined for all non-hydrogen atoms. Some of the hydrogen atoms could not be solved, so the analysis was not included. This paper contains additional crystallographic data CCDC number is 1897362 and 1897354.

In Cu-MOF-2, Cu(II) ion is connected by two BDC and imidazole ligands and each group connects two monomer units to form a 1D frame works (Fig. 4a), specified together with $x, y$ and $z$ axis to form 1D, 2D and 3D channels with a diameter of $\AA$ 12 (Fig. 4b, c).

\subsection{FTIR spectroscopy studies}

The FTIR spectra of Cu-MOF-1 and Cu-MOF-2 (Fig. 5) show a series of bands of $400-4000 \mathrm{~cm}^{-1}$. The Benzene-1, 4-dicarboxylic acid ring of the MOFs have given 


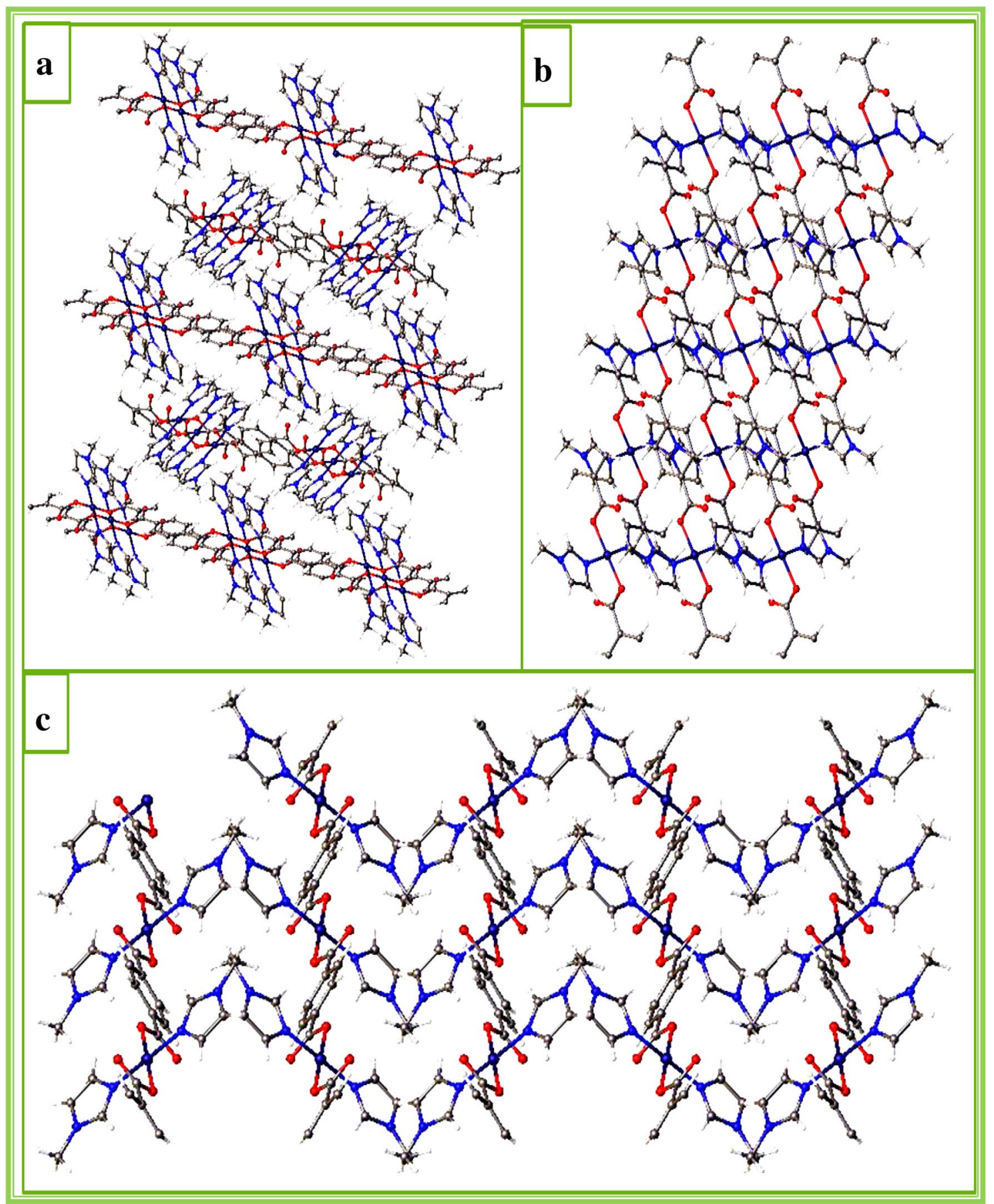

Fig. $4 \mathbf{a}, \mathbf{b}$ and $\mathbf{c}$ : Views of the coordination environment of Cu-MOF-2 with different axis $X, Y, Z$ (Symmetry transformations used to generate

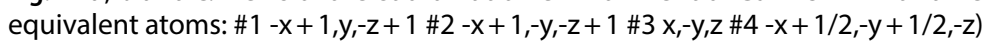

the signals at 3135 and $3555 \mathrm{~cm}^{-1}$ (-OH stretching); 2977 and $3124 \mathrm{~cm}^{-1}(\mathrm{C}-\mathrm{H}$ stretch of aromatic rings); 1607 and $1595 \mathrm{~cm}^{-1}\left(\mathrm{C}=\mathrm{O}\right.$ stretch); 1335 and $1356 \mathrm{~cm}^{-1}$ correspond to the asymmetrical and symmetrical stretch of carboxylate groups. The $1100,828 \mathrm{~cm}^{-1}$ and $1098,880 \mathrm{~cm}^{-1}$ peaks are corresponding to $\mathrm{C}-\mathrm{C}$ or $\mathrm{C}-\mathrm{O}-\mathrm{C}$ vibrations. The large bands of $3144 \mathrm{~cm}^{-1}$ could be assigned to the $\mathrm{N}-\mathrm{H}$ frequency of the Cu-MOF-2 imidazole ring. The vibration of the $\mathrm{C}-\mathrm{C}$ stretch has appeared at $1529 \mathrm{~cm}^{-1}$. The $\mathrm{N}-\mathrm{H}$ vibration stretching mode appeared at $3158 \mathrm{~cm}^{-1}$ of the compound. It is a very difficult task to identify the $\mathrm{C}-\mathrm{N}$ stretch frequency because it is possible give mixed bands in this region. The $\mathrm{C}-\mathrm{N}$ stretching vibration modes are appeared at 1463, 1227 and $1145 \mathrm{~cm}^{-1}$. 


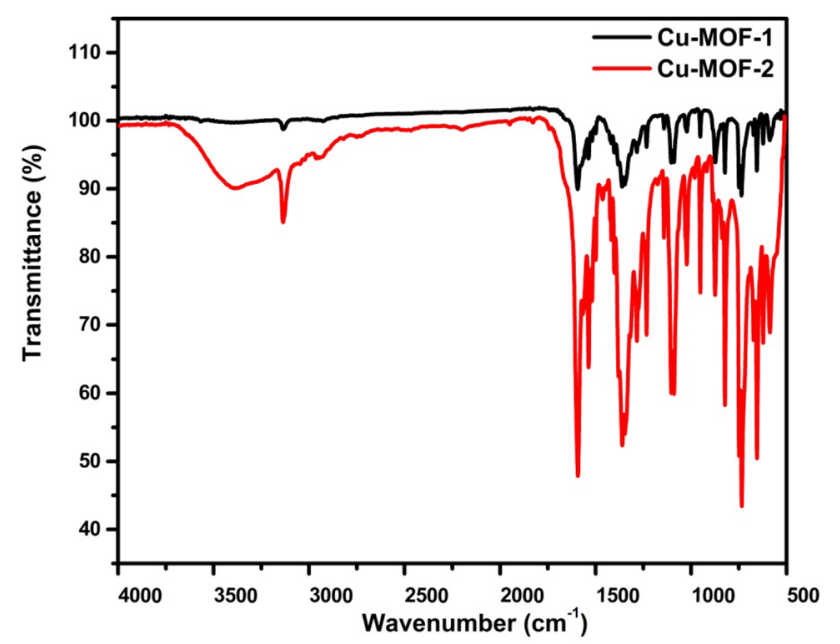

Fig. 5 FTIR spectrum of Cu-MOF-1 and Cu-MOF-2

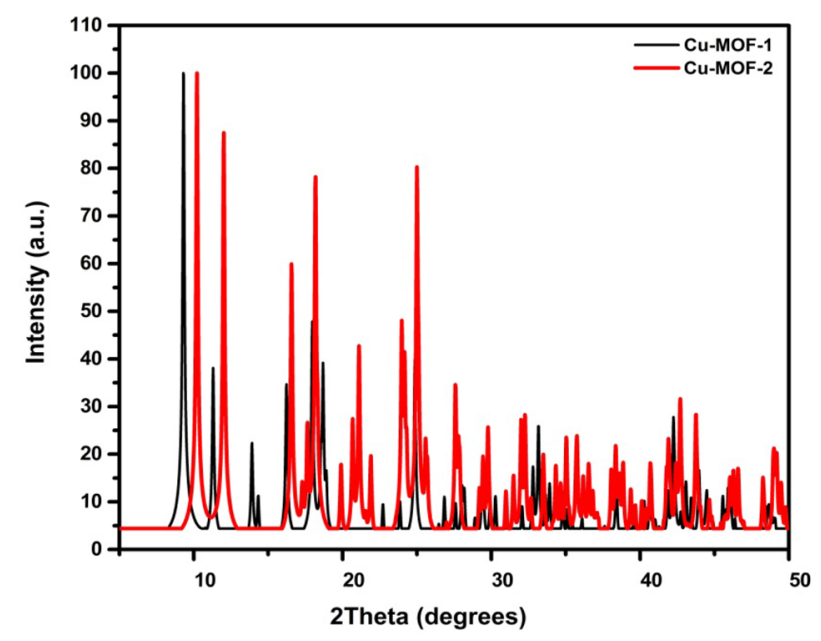

Fig. 6 PXRD patterns for Cu-MOF-1 and Cu-MOF-2

Thus, the FT-IR spectra of as-synthesized Cu-MOF-1 and Cu-MOF-2 yield strong structural confirmation [23-28].

\subsection{Powder X-ray diffraction (PXRD) studies}

Powder X-ray diffraction (PXRD) is a technique, which reveals the information about the nature of crystal structure and phase purity of the sample. The PXRD patterns of Cu-MOF-1 and Cu-MOF-2 show relatively high intensity peaks indicating the high crystallinity of the compounds (Fig. 6). The peak positions obtained are consistent with the standard parent material. High intensity Bragg diffraction peaks observed at $2 \theta=9.35^{\circ}, 11.31^{\circ}, 13.78^{\circ}$ and $16.16^{\circ}$ are correspond to Cu-MOF- 1 and those observed at $2 \theta=11.99^{\circ}, 16.42^{\circ}, 18.04^{\circ}$ and $24.0^{\circ}$ are for Cu-MOF-2. The highest intensity peaks in the $\mathrm{x}$-ray patterns for these MOFs are correspond to $2 \theta=9.35^{\circ}$ and $11.99^{\circ}$ respectively. This indicates the coordination of metal with the ligands to form complex. These results are consistent through the larger crystallite size and also an excellent crystalline nature can be seen.

\subsection{FE-SEM analysis}

FE-SEM is a technique that enables the microstructure and surface morphology of the product to be studied. Figure $7 \mathrm{a}-\mathrm{d}$ are the FE-SEM images of Cu-MOF-1 at various magnifications $(1,2,10$ and $20 \mu \mathrm{m})$. The Cu-MOF-1 images show the clusters of particles of irregular shapes with angles and sides.

Although Cu-MOF-2 images contain almost flat slabs like structures, they have been shown, the particles are visibly rich in flakes arranged as a cubic number of crystals and possibly have the same phase (as supported by XRD results).The FE-SEM images of Cu-MOF- 2 can be seen in various magnifications $(1,2,10$ and $20 \mu \mathrm{m})$ in the Fig. 8 .

\subsection{SEM-EDX analysis}

Analysis of the energy dispersive X-ray spectroscopy (EDX) was carried out to identify the elements present in the synthesized Cu-MOF-1 and Cu-MOF-2. The EDX pattern (Fig. 9a) of $\mathrm{Cu}-\mathrm{MOF}-1$ shows the $\mathrm{C}, \mathrm{O}$ and $\mathrm{Cu}$ elemental peaks with weight percentage and the $\mathrm{Cu}$ MOF-2 as well along with the nitrogen peaks. The EDX analysis thus confirms the basic composition of the $\mathrm{Cu}$ MOF-1 and Cu-MOF-2. The EDX results are summarized in Table 2.

\subsection{BET surface area measurement}

The porosity distribution of the Cu-MOF-1 and Cu-MOF-2 samples was analyzed for Barrett-Joyner-Halenda (BJH) method and $\mathrm{N}_{2}$ adsorption-desorption isotherms at $180^{\circ} \mathrm{C}$ for $4 \mathrm{~h}$. The Cu-MOF-1 and Cu-MOF-2 isotherm tests provide a distinctive IV- type curve with a different hysteresis loop within the range of $0.8-1.0 \mathrm{P} / \mathrm{P}_{\mathrm{o}}$ (Fig. 10), which indicates the existence of a mesoporous structure that in the two interconnected phases would usually be derived from the voids. The surface area of the BET is 12.9 and $12.7 \mathrm{~m}^{2} \mathrm{~g}^{-1}$ respectively for Cu-MOF-1 and 

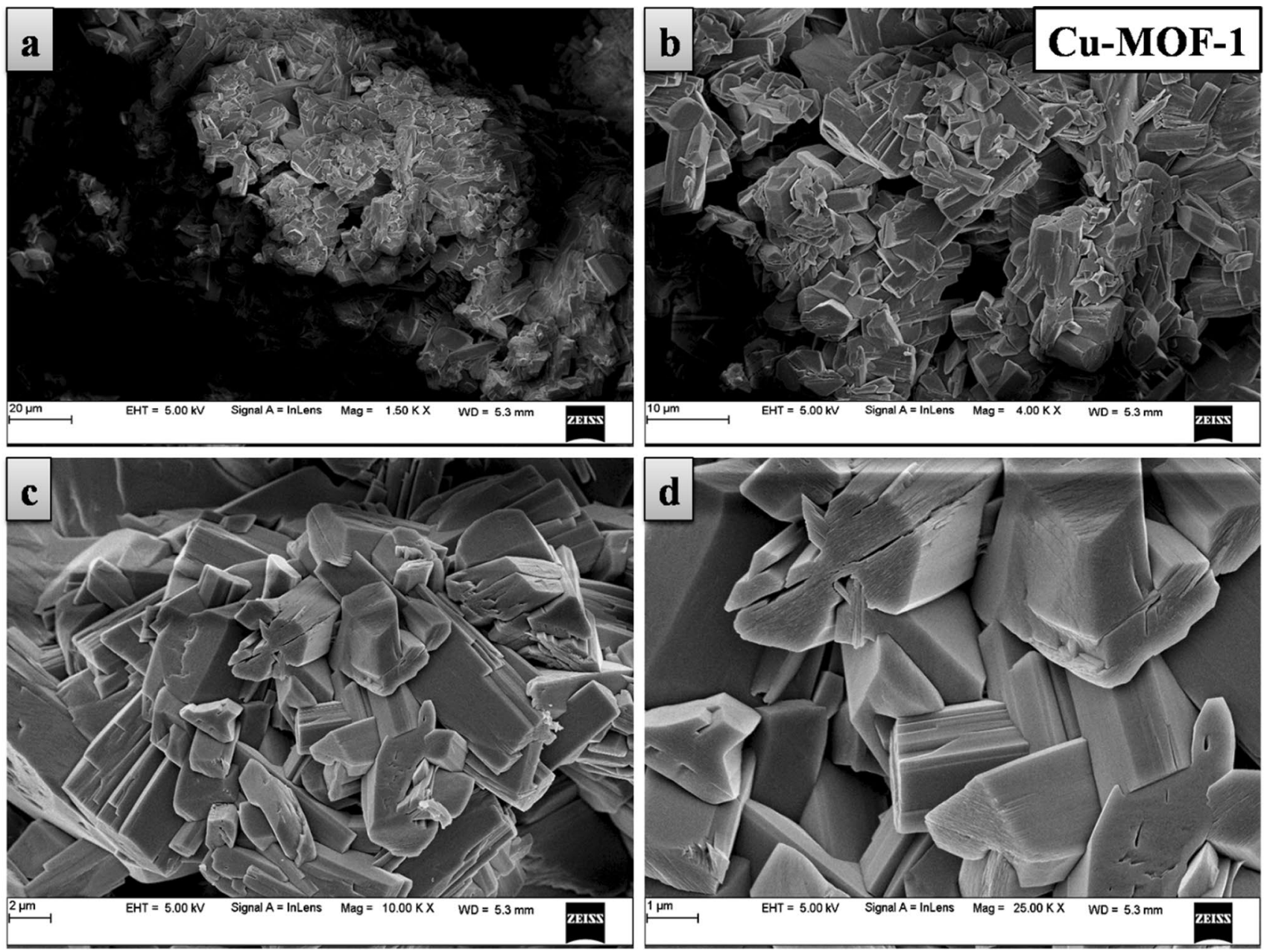

Fig. 7 FE-SEM micrographs of Cu-MOF-1 at different magnifications $(1,2,10$ and $20 \mu \mathrm{m})$

Cu-MOF-2. This mesoporous nature of $\mathrm{Cu}-\mathrm{MOF}-2$ can also play an important role in achieving large specific capacity due to its ability to facilitate the transport of diffusion/ions and ensure a high electrochemical active surface. The high volume of pores is beneficial for the rapid transport and diffusion of ions during the discharge process and therefore provides more electrically active energy storage sites. The Cu-MOF-2 hybrid's porous structure and large surface area is therefore likely to improve its performance in electrochemical applications.

\subsection{Thermo gravimetric analysis (TGA)}

Thermo gravimetric measurements for the MOFs were made at a heating rate of $20^{\circ} \mathrm{C} / \mathrm{min}$ under the $\mathrm{N}_{2}$ atmosphere without pre- treatment prior to the TG measurement. The Cu-MOF-1 and Cu-MOF-2 (Fig. 11) undergo weight loss at once each. The Cu-MOF-1 undergoes $40 \%$ weight loss between 150 and $300^{\circ} \mathrm{C}$, which could be due to the loss of DMF molecule. The weights loss of about $35 \%$ was observed in case of Cu-MOF-2 between 150 and $300{ }^{\circ} \mathrm{C}$, which could be attributed to the removal of the phenyl ring and carboxylate group. No such weight loss was observed until $500{ }^{\circ} \mathrm{C}$ later all the solvent molecules have disappeared and the frame work collapsed to yield final product. There is no peak for functional group in the figure showing collapsing of the compound at $600{ }^{\circ} \mathrm{C}$ due to the evaporation of solvent molecules. Both $\mathrm{Cu}$ MOF-1 and Cu-MOF-2 are stable in the temperature range of $200^{\circ} \mathrm{C}$.

\subsection{Electrochemical properties of Cu-MOF-1 and Cu-MOF-2}

The electrochemical measurements of $\mathrm{Cu}-\mathrm{MOF}-1$ and $\mathrm{Cu}$ MOF-2 electrodes were performed in an electrochemical (three-electrodes) cell containing an electrolyte of $6 \mathrm{M}$ 

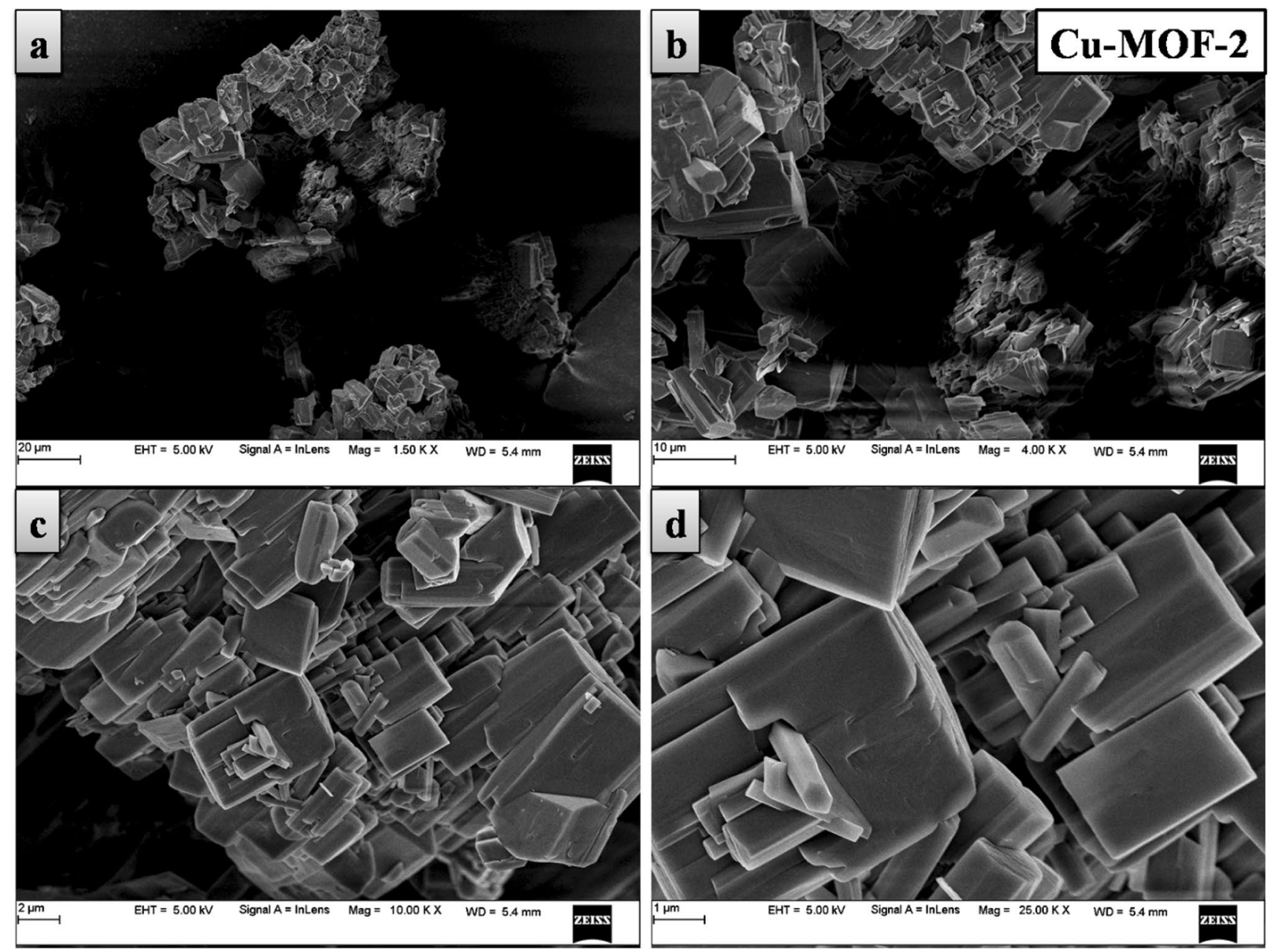

Fig. 8 FE-SEM micrographs of Cu-MOF-2 at different magnifications $(1,2,10$ and $20 \mu \mathrm{m})$
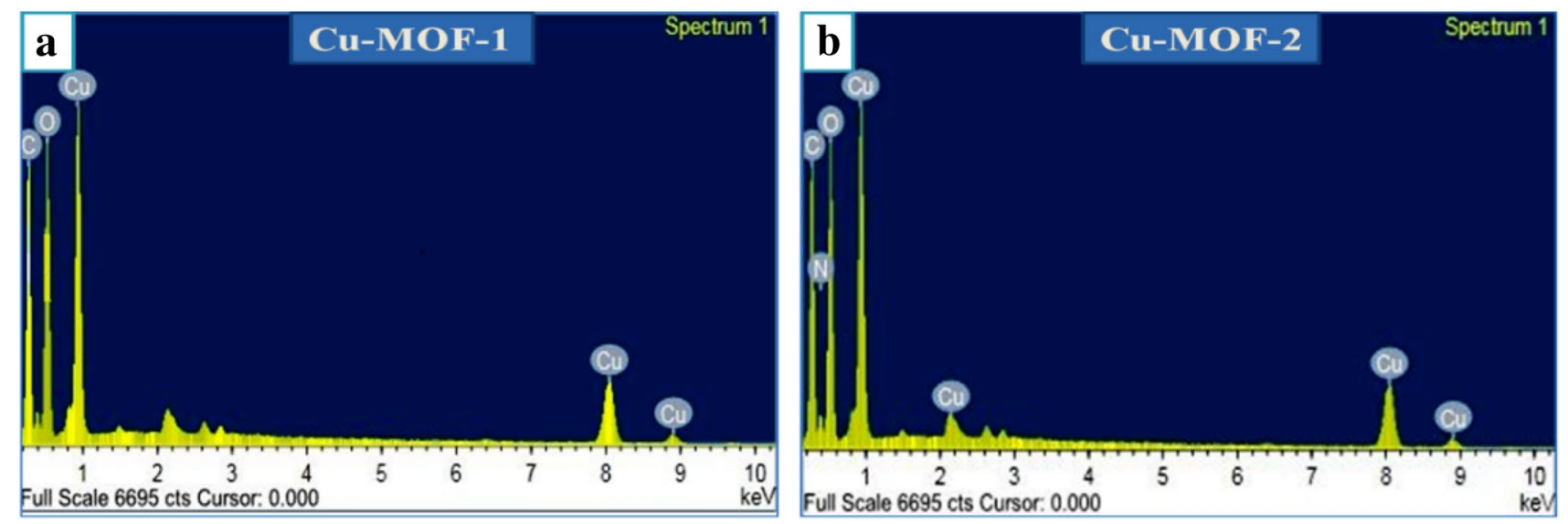

Fig. 9 Energy dispersive X-ray (EDX) pattern of Cu-MOF-1 and Cu-MOF-2 
Table 2 EDX data and elemental composition of Cu-MOF-1 and CuMOF-2

\begin{tabular}{llll}
\hline Compounds & Elements & Atomic \% & $\begin{array}{l}\text { Total } \\
\text { composi- } \\
\text { tion \% }\end{array}$ \\
\hline Cu-MOF-1 & $\mathrm{Cu}$ & 14.61 & 100 \\
& $\mathrm{C}$ & 24.36 & \\
Cu-MOF-2 & $\mathrm{O}$ & 48.73 & 100 \\
& $\mathrm{Cu}$ & 12.30 & \\
& $\mathrm{C}$ & 15.59 & \\
& $\mathrm{O}$ & 56.88 & \\
& $\mathrm{~N}$ & 27.53 & \\
\hline
\end{tabular}

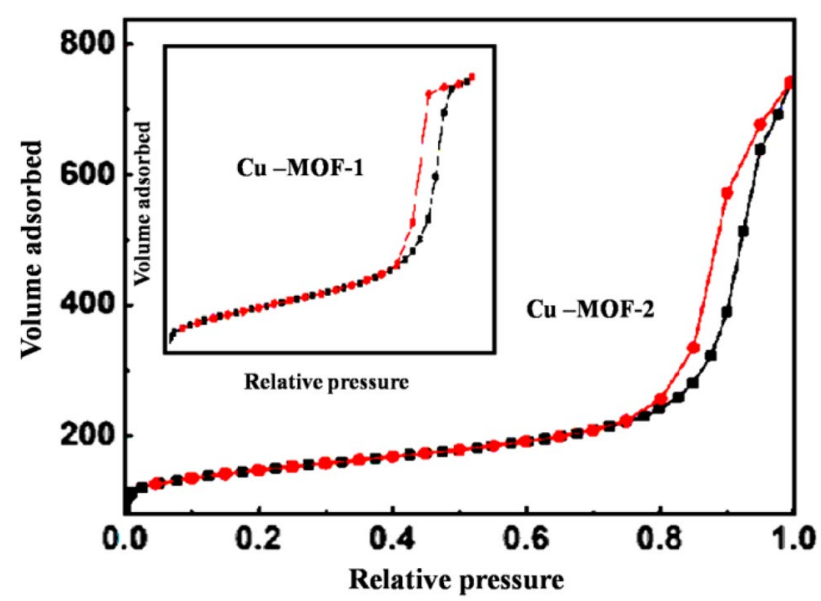

Fig. $10 \mathrm{~N}_{2}$ adsorption-desorption isotherms of $\mathrm{Cu}-\mathrm{MOF}-1$ and $\mathrm{Cu}$ MOF-2

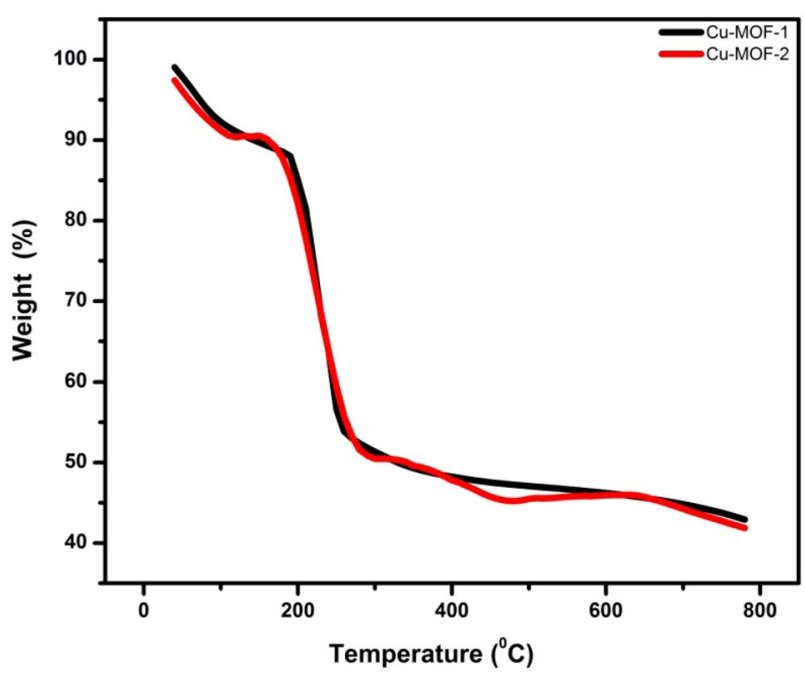

Fig. 11 Thermogravimetry curve of Cu-MOF-1 and Cu-MOF-2, which shows the weight loss regions
$\mathrm{KOH}$ solution. The cyclic voltammetry measurements were performed at different scanning rates $\left(10-100 \mathrm{mV} \mathrm{s}^{-1}\right)$ in the potential range is $0.0-0.5 \mathrm{~V}$ is shown in Fig. $12 \mathrm{a}$, b. The strong redox peaks present in each CV curve imply the Faradaic controlled reactions. The fine and sharp redox peaks of Cu-MOF-1 and Cu-MOF-2 can be perfectly related to the faradic reactions of the various oxidation states of $\mathrm{Cu}^{2+}$ and the route can be explained by the following reactions.

$$
\begin{aligned}
& \mathrm{Cu}(\mathrm{II})_{\mathrm{s}}+\mathrm{OH}^{-} \rightarrow \mathrm{Cu}(\mathrm{II})_{\mathrm{s}}+\mathrm{OH}_{\mathrm{ad}}^{-}+\mathrm{e}^{-} \\
& \mathrm{Cu}(\mathrm{II})_{\mathrm{s}}+\mathrm{OH}_{\mathrm{ad}}^{-} \rightarrow \mathrm{Cu}(\mathrm{III})_{\mathrm{s}}+\mathrm{OH}_{\mathrm{ad}}^{-}+\mathrm{e}^{-}
\end{aligned}
$$

According to Eq. 3, a high specific capacitance of 976 and $1048.8 \mathrm{~F} / \mathrm{g}^{-1}$ were attained at the scanning rate of $10 \mathrm{mV} / \mathrm{s}^{-1}$. With increase in scanning rate the oxidation peaks shift towards the positive direction and the reduction peaks shift towards the negative direction, which could be mainly due to the electrode internal resistance.

The CV curve area reflects the amount of charge stored in the electrodes presented in Fig. 12a, b. The specific capacitance can be calculated by the following equation.

$C_{S}=\frac{\int I d v}{v m V}$

If $\mathrm{Cs}$ is the specific capacity $(\mathrm{F} / \mathrm{g})$, I is the current $(\mathrm{A})$, $\mathrm{v}$ is the scanning rate $(\mathrm{mV} / \mathrm{s}), \mathrm{m}$ is the active material weight (g) and $v$ is the potential window (V).

The galvanostatic charge and discharge curves (GCDs) for Cu-MOF-1 and Cu-MOF-2 are shown in Fig. 13a, b respectively. The calculated specific capacities of $\mathrm{Cu}$ MOF-1 and Cu-MOF-2 at the current density of $1 \mathrm{~A} \mathrm{~g}^{-1}$ are 181.65 and $248.44 \mathrm{~F} \mathrm{~g}^{-1}$ respectively. Figure $13 \mathrm{c}$ shows the Cu-MOF-1 and Cu-MOF-2 specific capacitance is decreases, and the current density is steadily increases [29]. The discharge time of the Cu-MOF-2 electrode has increased notably when compared to Cu-MOF-1 electrodes (Fig. 13b). The specific capacitance of the materials can be calculated based on the following equation from the galvanostatic discharge curves.

$C_{S}=\frac{I \times \Delta t}{\Delta V \times m}$

where I is the current (A); $t$ is the discharge time $(s), v$ is the potential $(\mathrm{V})$ and $\mathrm{m}$ is the mass of the active material on the electrode [30, 31].

The rapid transport of electrolytes in large voids between the two phases of Cu-MOF-1 and Cu-MOF- 2 can be attributed to this outstanding performance and an extensive cyclic stability up to 2000 cycles with capacity retention of $\sim 90.1 \%$. The better long- term constancy of the Cu-MOFs electrode shows that it can be a good 

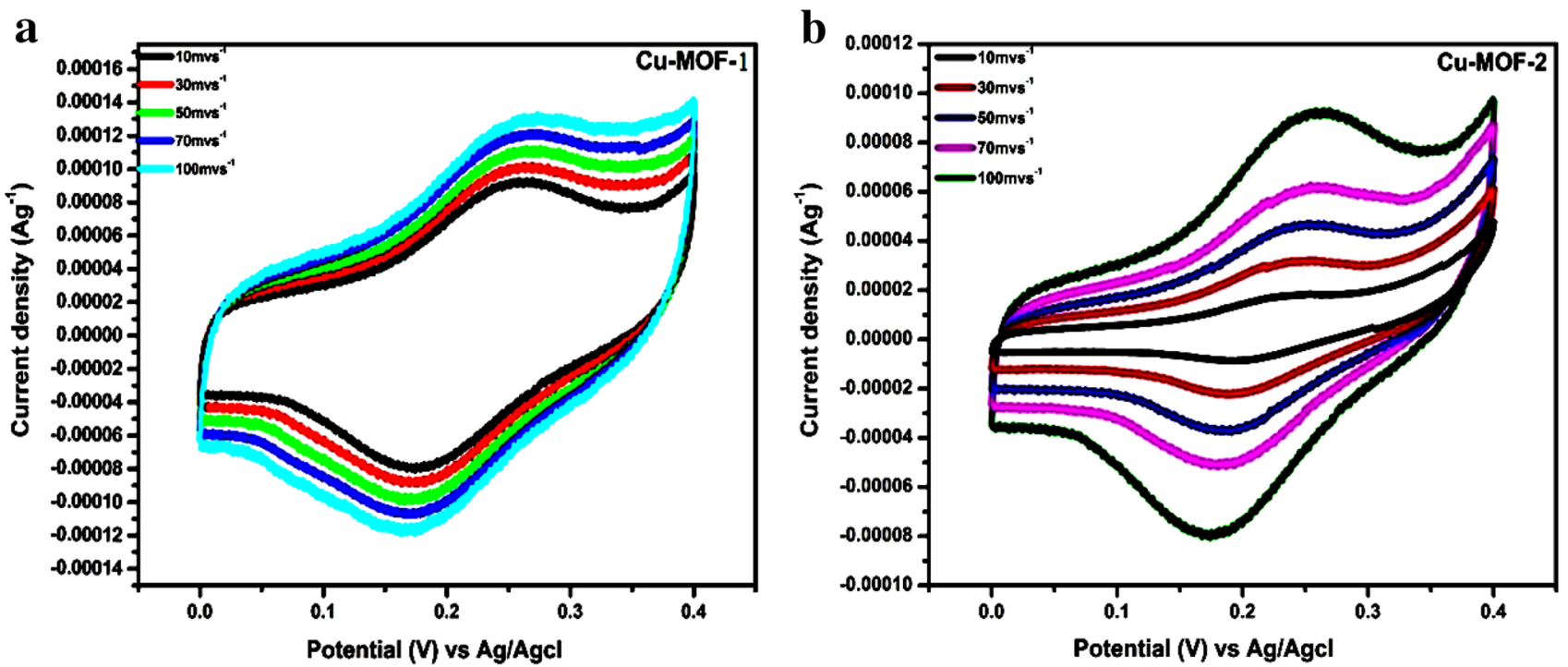

C

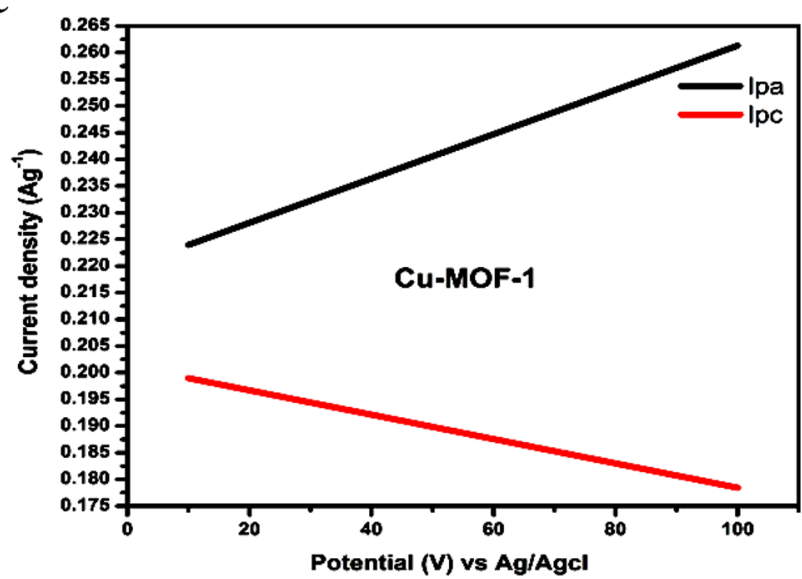

Fig. $12 \mathbf{a}$ and $\mathbf{b}$ are the CVs of Cu-MOF-1 and Cu-MOF-2 electrodes respectively in a $6 \mathrm{M} \mathrm{KOH}$ solution at different scan rates between $10-100 \mathrm{mV} \mathrm{s}^{-1}, \mathbf{c}$ and $\mathbf{d}$ are the Relationships between the graph of

material for applications for super capacitors. The power density $(P)$ and the energy density (E) can be calculated from the following equations.

Energy density $E=\frac{1}{2} C V^{2}$

Power density $P=\frac{E}{t}$

where $\mathrm{C}\left(\mathrm{F} / \mathrm{g}^{-1}\right), \mathrm{V}(\mathrm{V}), \mathrm{P}(\mathrm{W} / \mathrm{kg}), \mathrm{E}(\mathrm{Wh} / \mathrm{kg})$, and $\mathrm{t}(\mathrm{s})$ are the specific capacitance, potential window, power density, energy density and discharge time respectively $[32,34]$.

d

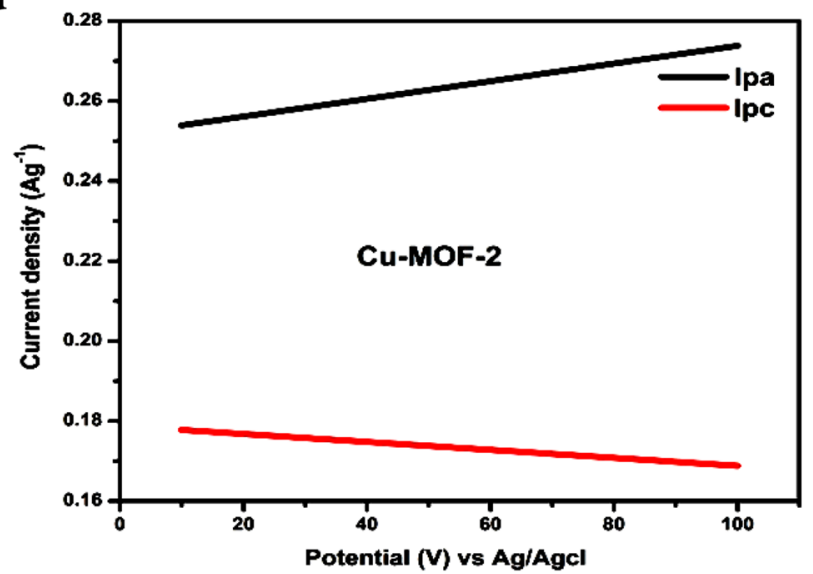

anodic peak current (Ipa) versus square root of scan rate $\left(v^{1 / 2}\right)$ was plotted in the Cu-MOF-1 and Cu-MOF-2 electrodes

\subsection{Electrochemical impedance spectroscopy (EIS)}

Electrochemical impedance spectroscopy (EIS) measurements were made at a frequency range of $100 \mathrm{kHz}$ to $0.01 \mathrm{~Hz}$ with a disturbance potential of $5 \mathrm{mV} \mathrm{s}^{-1}$ as shown in Fig. 13d.The Cu-MOF-1 semicircles in the high frequency range are smaller than the Cu-MOF-2 semicircles. A smaller semi-circle indicate a small charge- transfer resistance(Rct) [32], the straight lines in the low-frequency region show an ideal electrode capacitive behaviour, while the calculated Rct for Cu-MOF-1 and Cu-MOF-2 are 6.23 and $7.4 \Omega$ respectively. The interception of the real axis in the high frequency range of Nyquist plots indicates the equivalent series resistance (ESR), the combined series resistance of electrolytes, electrodes, electrolytes and electrodes [35, 36]. The Cu-MOF-1 and Cu-MOF-2 ESRs are 4.58 and $3.48 \Omega$ respectively (Table 3 ). 

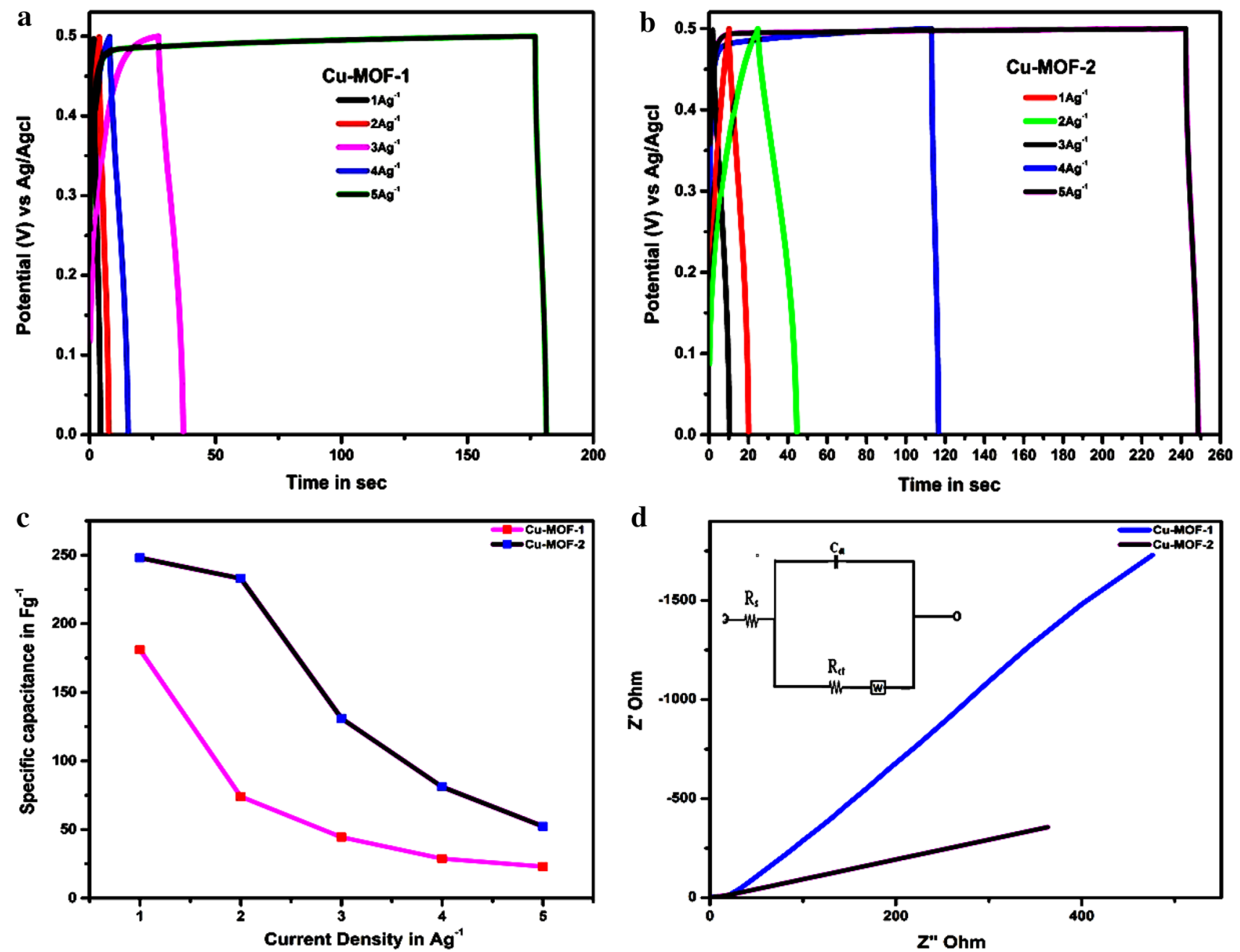

Fig. 13 a and b Galvanostatic Charge/discharge curves of CuMOF-1 and Cu-MOF-2 at different current densities, c variation of specific capacitance as a function of current density and $\mathbf{d}$ Nyquist

plot and Equivalent Circuits of Cu-MOF-1 and Cu-MOF-2 electrodes in $6 \mathrm{M} \mathrm{KOH}$ Solution

\section{Conclusions}

Table 3 Power density (P) and the energy density (E) of Cu-MOF-1 and Cu-MOF-2 with different current densities

\begin{tabular}{llll}
\hline Compounds & $\begin{array}{l}\text { Current densi- } \\
\text { ties }\left(\mathrm{A} / \mathrm{g}^{-1}\right)\end{array}$ & $\begin{array}{l}\text { Energy density } \\
(\mathrm{W} \mathrm{h} / \mathrm{kg})\end{array}$ & $\begin{array}{l}\text { Power } \\
\text { density }(\mathrm{W} / \\
\mathrm{kg})\end{array}$ \\
\hline Cu-MOF-1 & 1 & 22.62 & 124 \\
& 2 & 9.25 & 249 \\
& 3 & 5.55 & 375 \\
& 4 & 3.60 & 500 \\
Cu-MOF-2 & 5 & 2.87 & 623 \\
& 1 & 31.0 & 125 \\
& 2 & 29.12 & 251 \\
& 3 & 16.45 & 374 \\
& 4 & 10.13 & 499 \\
& 5 & 6.53 & 624 \\
\hline
\end{tabular}

The Cu-MOF-1 and Cu-MOF-2 have been successfully synthesized by solvothermal methods. The Cu-MOF crystals are the mass of many thin mesoporous structures bearing a larger surface area. The electrochemical properties of the Cu-MOF-1 and Cu-MOF-2 electrodes have been studied to understand them for the supercapacitor application. The Cu-MOF-1 and Cu-MOF-2 electrode showed a maximum specific capacity of 181 and $248 \mathrm{~F} \mathrm{~g}^{-1}$ at a current density of $1 \mathrm{~A} \mathrm{~g}^{-1}$. Moreover, the materials deliver high energy and power density and excellent rate performance with long cycle life as we studied. The Cu-MOF-2 showed improved electrochemical performance compared to the Cu-MOF-1. Our results show that $\mathrm{Cu}$ (bdc) MOFs are highly promising to be used as an advanced electrode material for highperformance super capacitor applications. 


\section{Supplementary material}

Crystallographic information has been deposited with the Cambridge Crystallographic Data Centre, CCDC No. 1897362 and 1897354. The Director, CCDC12 Union Road, Cambridge CB2 1EZ, UK (fax: +44-1223-336-033; e-mail:deposit@ccdc.cam.ac.uk).

Acknowledgements The authors like to acknowledge Bangalore University (SC/ST Cell) for financial support (fellowship). We also like to acknowledge Dr P. Raghavendra Kumar, University College of science Tumkur University for the cyclic voltammetry study.

\section{Compliance with ethical standards}

Conflict of interest The authors declare that they have no conflict of interest.

\section{References}

1. Zhang Y, Bo X, Luhana C, Wang H, Li M, Guo L (2013) Facile synthesis of a Cu-based MOF confined in macro porous carbon hybrid material with enhanced electro catalytic ability. Chem Commun 49:6885-6887

2. Travlou NA, Singh K, Rodriguez-Castellon E, Bandosz TJ (2015) $\mathrm{Cu}$-BTC MOF-graphene-based hybrid materials as low concentration ammonia sensors. Mater Chem A 3:11417-11429

3. Ramaraju B, Li CH, Prakash S, Chen CC (2016) Metal-organic framework derived hollow polyhedron metal oxide posited graphene oxide for energy storage applications. Chem Commun 52:946-949

4. Wang Y, Wu Y, Xie J, Hu X (2013) Metal-organic framework modified carbon paste electrode for lead sensor. Sens Actuator B Chem 17:1161-1166

5. Hosseini H, Ahmar H, Dehghani A, Bagheri A, Tadjarodi A, Fakhari AR (2013) A novel electrochemical sensor based on metalorganic framework for electro-catalytic oxidation of L-cysteine. Biosens Bioelectron 42:426-429

6. Xia W, Mahmood A, Zou R, Xu Q (2015) Metal-organic frameworks and their derived nanostructures for electrochemical energy storage and conversion. Energy Environ Sci 8:1837-1866

7. Srimuk $P$, Luanwuthi S, Krittayavathananon A, Sawangphruk M (2015) Solid-type supercapacitor of reduced graphene oxidemetal organic framework composite coated on carbon fiber paper. Electrochim Acta 157:69-77

8. Zhang S, Li D, Chen S, Yang X, Zhao X, Zhao Q, Komarneni S, Yang DJ (2017) Highly stable supercapacitors with MOF-derived $\mathrm{Co}_{9} \mathrm{~S}_{8}$ /carbon electrodes for high rate electrochemical energy storage. Mater Chem A 5:12453-12461

9. Krishnamurthy G, Omkaramurthy BM, Sangeetha S (2018) Nickel and Cobalt Metal-organic frameworks as advanced electrode materials for electrochemical energy storage and ion sensor application. IJSEM 3(2)

10. Omkaramurthy BM, Krishnamurthy G (2019) Electrocatalytic activity and chemical sensor application of Mn-MOF: synthesis, crystal structure and photo luminescent properties. Mater Res Express 6:125544
11. Yamada T, Shiraishi K, Kitagawa H, Kimizuka N (2017) Applicability of MIL-101(Fe) as a cathode of lithium ion batteries. Chem Commun 53:8215-8218

12. Lei Y, Gan M, Ma L, Jin M, Zhang X, Fu G, Yang P, Yan M (2017) Synthesis of nitrogen-doped porous carbon from zeolitic imidazolate framework- 67 and phenolic resin for high performance supercapacitors. Ceram Int 43:6502-6510

13. Elanthamilan E, Sarala L, Bella A, Sathiyan A, Lydia S, Sundar Manoharan S, Princy Merlin J (2017) Electro-organic synthesis of 2-(4,5-diphenyl-1H-imidazol-2-yl)phenol in Aqueous medium for organic monomer based Supercapacitor electrode. Electrochim Acta 251:32-42

14. Zhao Y, Song Z, Li X, Sun Q, Cheng N, Lawes S, Sun X (2016) Metal organic frameworks for energy storage and conversion. Energy Storage Mater 2:35-62

15. Wang X, Liu X, Rong H, Song Y, Wen H, Liu Q (2017) Layered manganese-based metal-organic framework as a high capacity electrode material for supercapacitors. RSC Adv 7:29611-29617

16. Heydari H, Moosavifard SE, Elyasi S, Shahraki M (2017) Nanoporous CuS nano-hollow spheres as advanced material for high-performance supercapacitors. Appl Surf Sci 394:425-430

17. Muniraj VKA, Kamaja CK, Shelke MV (2016) $\mathrm{RuO}_{2} \mathrm{nH}_{2} \mathrm{O}$ nanoparticles anchored on carbon nano-onions: an efficient electrode for solid state flexible electrochemical supercapacitor. ACS Sustain Chem Eng 4:2528-2534

18. Krishnamoorthy K, Veerasubramani G, Pazhamalai P, Kim SJ (2016) Designing two dimensional nanoarchitectured $\mathrm{MoS}_{2}$ sheets grown on Mo foil as a binder free electrode for supercapacitors. Electrochim Acta 190:305-312

19. Omkaramurthy BM, Krishnamurthy G (2019) Synthesis characterization, crystal structure, and electrochemical study of zinc(II) metal-organic framework. Inorganic Nano-Metal Chem 49:375-384

20. Xia H, Zhang J, Yang Z et al (2017) 2D MOF nanoflake-assembled spherical microstructures for enhanced supercapacitor and electrocatalysis performances. Nano-Micro Lett 9:43

21. Krishnamurthy G, Omkaramurthy BM, Sangeetha S (2017) Mn and $\mathrm{Co}$, metal-organic frameworks for hydrogen gas (energy) storage and heavy metal ion sensor application for clean environment. IJSEM 2(12)

22. Patel JP, Xiang ZG, Hsu SL, Schoch AB, Carleen SA, Matsumoto D (2015) Path to achieving molecular dispersion in a dense reactive mixture. J Polym Sci Part B Polym Phys 53:1519-1526

23. Patel JP, Deshmukh S, Zhao C, Wamuo O, Hsu SL, Schoch AB, Carleen SA, Matsumoto D (2016) An analysis of the role of nonreactive plasticizers in the crosslinking reactions of a rigid resin. J Polym Sci Part B Polym Phys 55:206-213

24. Patel JP, Deshmukh S, Zhao C, Wamuo O, Hsu SL, Schoch AB, Carleen SA, Matsumoto D (2016) An analysis of the role of reactive plasticizers in the crosslinking reactions of a rigid resin. Polymer 107:12-18

25. Patel JP, Xiang ZG, Hsu SL, Schoch AB, Carleen SA, Matsumoto $D$ (2017) Characterization of the cross linking reaction in high performance adhesives. Int J Adhes Adhes 78:256

26. Patel JP, Hsu SL (2018) Development of low field NMR technique for analyzing segmental mobility of crosslinked polymers. J Polym Sci Part B Polym Phys 56:639

27. Patel JP. Doctoral Dissertations. https://scholarworks.umass.edu/ dissertations 2/1116

28. Wang L, Han Y, Feng X, Zhou J, Qi P, Wang B (2016) Metalorganic frameworks for energy storage: batteries and supercapacitors. Coordin Chem Rev 307:361-381

29. Saraf M, Rajak R, Mobin SM (2016) A fascinating multitasking $\mathrm{Cu}-\mathrm{MOF} / \mathrm{rGO}$ hybrid for high performance supercapacitors 
and highly sensitive and selective electrochemical nitrite sensors. J Mater Chem A 4:16432-16445

30. Banerjee A, Singh U, Aravindan V, Srinivasan M, Ogale S (2013) Synthesis of $\mathrm{CuO}$ nanostructures from $\mathrm{Cu}$-based metal organic framework (MOF-199) for application as anode for Li-ion batteries. Nano Energy 2:1158-1163

31. Krishnamurthy G, Shivakumar MS (2017) Electroless deposition of nanosized nickel over graphite substrate with better coating coverage and catalytic activity for fuel cell application. J Appl Electrochem 47:519-529

32. Zhou G, Zhu J, Chen YJ, Mei L, Duan XC, Zhang GH, Chen LB, Wang TH, Lu BG (2014) Simple method for the preparation of highly porous $\mathrm{ZnCo2O} 4$ nanotubes with enhanced electrochemical property for supercapacitor. Electrochem Acta 123:450-455

33. Wang $C$, Huang $Y, X u Y$, Jiao $L$, Yuan $\mathrm{H}$ (2014) Porous $\mathrm{NiCO}_{2} \mathrm{O}_{4}$ nanostructures for high performance supercapacitors via a microemulsion technique. Nano Energy 10:125-134
34. Gao Z, Wang F, Chang J, Wu D, Wang X, Wang X, Xu F, Gao S, Jiang $\mathrm{K}$ (2014) Chemically grafted graphene-polyaniline composite for application in supercapacitor. Electrochim Acta 133:325-334

35. Liu Y, Zhang Y, Chen J, Pang H (2014) Copper metal-organic framework nanocrystal for plane effect nonenzymatic electrocatalytic activity of glucose. Nanoscale 6:10989-10994

36. Hosseini H, Ahmar H, Dehghani A, Bagheri A, Tadjarodi A, Fakhari AR (2013) Au-SH-SiO 2 nanoparticles supported on metal-organic framework (Au-SH-SiO ${ }_{2} @ \mathrm{Cu}-\mathrm{MOF}$ ) as a sensor for electrocatalytic oxidation and determination of hydrazine. Electrochim Acta 88:301-309

Publisher's Note Springer Nature remains neutral with regard to jurisdictional claims in published maps and institutional affiliations. 